\title{
MOTIVASI MENJADI HOST COUCHSURFING DI INDONESIA
}

\author{
Rozzana Deskanti ${ }^{1}$, Adi Bayu Mahadian ${ }^{2}$ \\ 1'rozza.deskanti@gmail.com \\ Program Studi Ilmu Komunikasi, Fakultas Komunikasi dan Bisnis, Universitas Telkom \\ ªdibayumahadian@telkomuniversity.ac.id \\ Program Studi Ilmu Komunikasi, Fakultas Komunikasi dan Bisnis, Universitas Telkom
}

\begin{abstract}
Being a host is part of a new tourism activity in Indonesia known as free hospitality, the activity has a great potential but need encouragement to the actors. In the digital era new tourism actors are spread and connected via the internet, couchsurfing is one of the social media that is present in the development of tourism communication and as a liaison between actors of activities, encouragement is needed to motivate tourism growth in this sector. This study aims to know the highest level of motivation and motivator factors that can be used for government policy making. Motivation is one of the driving factors that influences a person to do something that is intended. This study uses descriptive quantitative methods with one variable. The independent variable in this study is motivation to become a couchsurfing host. The analysis technique used is descriptive analysis technique. This research was conducted by distributing questionnaires to 100 respondents by combining two nonprobability sampling techniques, namely purposive sampling and quota sampling. The results of this study state that the motivation to host couchsurfing in Indonesia is in the high category with an amount of $75.1 \%$ and the highest motivation is in the cultural factor of $94 \%$. The conclusion of this study is that actors want to carry out cultural exchanges, by being a host, local residents can use their knowledge of the culture and local area to attract tourist visits.
\end{abstract}

\begin{abstract}
Abstrak: Menjadi host/tuan rumah merupakan bagian dari kegiatan pariwisata baru di Indonesia yang dikenal sebagai free hospitality/keramah tamahan, kegiatan tersebut memiliki potensi besar namun perlu dorongan terhadap pelakunya. Di era digital para pelaku pariwisata baru tersebar dan terkoneksi melalui internet, Couchsurfing merupakan salah satu media sosial yang hadir dalam perkembangan komunikasi pariwisata dan sebagai penghubung antar pelaku kegiatan, diperlukan dorongan untuk memotivasi pertumbuhan pariwisata di sektor ini. Studi ini bertujuan untuk mengetahui tingkat motivasi dan faktor motivator tertinggi yang dapat digunakan untuk pengambilan kebijakan pemerintah. Motivasi merupakan salah satu faktor pendorong yang mempengaruhi seseorang untuk melakukan suatu hal yang ditujunya. Penelitian ini menggunakan metode kuantitatif deskriptif dengan satu variabel. Variabel independen dalam penelitian ini adalah motivasi menjadi host couchsurfing. Teknik analisis yang digunakan adalah teknik analisis deskriptif. Penelitian ini dilakukan dengan menyebar kuesioner kepada 100 responden dengan menggabungkan dua teknik pengambilan sampel nonprobability yaitu : pengambilan sampel purposive, dan pengambilan sampel kuota. Hasil dari penelitian ini menyatakan bahwa motivasi menjadi host couchsurfing di Indonesia berada dalam kategori tinggi dengan jumlah sebesar $75,1 \%$ dan motivasi tertinggi ada pada faktor kebudayaan sebesar 94\%. Kesimpulan dari penelitian ini adalah para pelaku ingin melakukan pertukaran budaya, dengan menjadi host, warga lokal bisa memanfaatkan pengetahuannya tentang budaya dan daerah setempat untuk menggaet kunjungan wisatawan.
\end{abstract}

Keywords: communication, motivation, host couchsurfing. 


\section{PENDAHULUAN}

Indonesia merupakan negara kepulauan yang memiliki berbagai macam sumber daya alam yang terdiri dari lautan, daratan, matahari dan pantai. Sumber daya alam itu dapat menjadi modal yang bisa dimanfaatkan dalam kegiatan berwisata, yang dimana dapat memberikan keuntungan besar bagi negara apabila dikelola dengan baik dan benar. Menururt Chandra \& Darmajati (2017) menyatakan bahwa sektor pariwisata Nasional kini menjadi primadona baru bagi pembangunan Nasional. Sumbangan devisa maupun penyerapan tenaga kerja dalam sektor ini amat signifikan bagi devisa negara. Bahkan, diperkirakan pada 2019 sudah mengalahkan pemasukan devisa dari industri kelapa sawit (CPO). Indonesia saat ini memiliki potensi pariwisata yang sangat beragam namun belum bisa di manfaatkan secara maksimal karena saat ini Indonesia masih mengandalkan wisata-wisata konvensional dalam menarik kunjungan para wisatawan. Prastowo dan Budiana (2016) mengatakan bahwa turis asing dari berbagai negara lebih tertarik menikmati objek wisata yang kondisinya masih alami. Pengembangan pariwisata berbasis alam dengan menonjolkan budaya dan kearifan lokal atau "ecotourism", kini mulai banyak dilirik berbagai daerah untuk menggaet kunjungan wisatawan, khususnya dari mancanegara.

Masyarakat lokal yang tinggal di sekitar daerah potensi wisata saat ini bisa dengan mudah memperkenalkan daerahnya melalui media sosial yang penggunaannya sudah terhubung dengan internet. Dimana pada zaman ini, internet merupakan sesuatu yang lazim digunakan bahkan bisa dikatakan internet sudah menjadi kebutuhan bagi manusia abad ini di seluruh dunia. Media sosial adalah salah satu kegiatan online paling terkenal dengan tingkat pengguna yang tinggi. Media sosial memiliki berbagai macam jenis diantaranya yang adalah Facebook, Twitter, Youtube, Instagram, dan sebagainya. Hasil dari data Statista.com menyatakan bahwa jumlah pengguna media sosial di seluruh dunia pada tahun 2017 diperkirakan akan ada sekitar 2,77 miliar, naik dari 2,46 miliar pada tahun 2017 (The Statistics Portal, 2018).

Di era berkembangnya teknologi saat ini juga memberikan dampak terhadap perkembangan komunikasi pariwisata, dimana masyarakat Indonesia yang melek akan teknologi dan sadar akan potensi wisata di daerahnya mulai turut berkontribusi dalam mengembangkan pariwisata di daerahnya melalui cara baru dalam berwisata yaitu free hospitality atau kesediaan menerima tamu gratis. Menurut Pietilä (2011) kesediaan menerima tamu secara gratis adalah sektor yang berkembang di industri pariwisata. Saat ini jutaan orang di seluruh dunia memanfaatkan jaringan online yang menyediakan kesedian menerima tamu gratis untuk pelancong di seluruh dunia. Anggota keramah tamahan online atau free hospitality online terbesar saat ini adalah Couchsurfing, yang memiliki lebih dari 12 juta anggota di seluruh dunia yang saling menawarkan akomodasi bantuan dirumah mereka secara gratis. Couchsurfing merupakan satu-satunya platform media sosial yang memiliki fitur "become a host". Di Indonesia sendiri perkembangan jumlah anggota Couchsurfing yang menjadi host meningkat sejak 6 September 2018 sampai 9 November 2018 sebanyak 8.738 sehingga menjadi 281.531 hosts (Couchsurfing, 2018). Couchsurfing merupakan fenomena yang menarik untuk diteliti karena saat ini masih sedikit penelitian yang menjadikan itu sebagai bahan penelitian terutama mengenai motivasi para anggota Couchsurfing yang menjadi host."Motif berasal dari bahasa latin movere yang berarti bergerak atau to move" (Branca dalam Walgito, 2004:220). Sedangkan pendapat Woodworth (dalam Sobur, 2016 : 233) mengartikan motif sebagai suatu set yang dapat atau mudah menyebabkan individu untuk melakukan kegiatan-kegiatan tertentu (berbuat sesuatu) dan untuk mencapai tujuantujuan tertentu. Penelitian ini menggunakan tiga teori motivasi yaitu; Teori Hierarki Kebutuhan Maslow, Teori Motivasi Dua Faktor Herzberg, dan Teori Motivasi Vroom.

Teori yang digunakan dalam penelitian ini berlandaskan dari penelitian terdahulu yang dibuat oleh Pietila (2011) tentang Motivasi menjadi host Couchsurfing di Spanyol. Pietila (2011) menggunakan teori kebutuhan hierarki Maslow, teori motivasi dua faktor Herzberg, teori harapan Vroom serta konsep sistem penghargaan dan motivasi untuk berpartisipasi dalam komunitas online.

Penelitian ini bertujuan untuk mencari tahu seberapa besar motivasi yang dimiliki para anggota host Couchsurfing di Indonesia dan apa yang menjadi motivasi terbesar 
mereka sehingga mereka ingin membukakan pintu rumah mereka secara gratis kepada wisatawan.

\section{METODE}

Penelitian ini juga menggunakan pendekatan kuantitatif dengan metode analisis deskriptif. Penelitian deskriptif merupakan penelitian yang berusaha mendeskripsikan suatu gejala, peristiwa dan kejadian yang terjadi pada saat sekarang dimana peneliti berusaha memotret peristiwa dan kejadian yang menjadi pusat perhatian untuk kemudian digambarkan sebagaimana adanya (Sudjana \& Ibrahim, 1989:64).

Peneliti menggunakan penelitian deskriptif karena dalam penelitian ini hanya memiliki satu variabel, penelitian ini pun dilakukan untuk mengukur nilai tertinggi dari setiap pernyataan dalam sebuah dimensi yang ada, dan kemudian hasil dalam penelitian ini akan disampaikan dalam sebuah gambar atau grafis sederhana. Tidak untuk menguji teori yang yang digunakan.

Teknik pengumpulan data yang dilakukan adalah dengan kuesioner elektronik. Menurut Sugiyono (2018:219), kuesioner merupakan teknik pengumpulan data yang dilakukan dengan cara memberi seperangkat pertanyaan atau pernyataan tertulis kepada responden untuk dijawabnya. Menurut Sue \& Ritter (dalam Kettunen, 2017), Kuesioner elektronik memiliki kelebihan, karena menawarkan cara cepat, murah dan efisien untuk melakukan survei dari wilayah geografis yang luas. Kuesioner elektronik dibuat melalui google form, kemudian tautan akan disebar luaskan di situs web Couchsurfing sesuai dengan populasi dan sampel yang telah ditentukan.

\section{HASIL DAN PEMBAHASAN}

Berdasarkan hasil penyebaran kuesioner kepada 100 anggota host Couchsurfing di Indonesia mengenai motivasi menjadi host Couchsurfing memiliki nilai rata-rata sebesar 3,78 yang saat diletakkan pada garis kontinum sesuai rumus yang digunakan berada dalam kategori "tinggi". Tingkat motivasi menjadi host Couchsurfing di Indonesia yang berada dalam kategori "tinggi" didapat dari hasil perhitungan dua faktor motivasi yang termasuk dalam kategori "sangat tinggi" yaitu; faktor kebudayaan $(4,70)$ \& faktor perkembangan diri $(4,39)$, ditambah tiga faktor motivasi dalam kategori "tinggi" yaitu; faktor komunitas $(4,03)$, faktor sosial $(3,80)$ \& faktor kebutuhan harga diri $(3,52)$, dan ditambah dua faktor motivasi dalam kategori "sedang" yaitu; faktor timbal-balik $(3,24) \quad \&$ faktor penghargaan $(2,81)$.

\begin{tabular}{|l|l|l|l|l|}
\hline $\begin{array}{c}\text { Sangat } \\
\text { Rendah }\end{array}$ & Rendah & Sedang & Tinggi & $\begin{array}{r}\text { Sangat } \\
\text { Tinggi }\end{array}$ \\
\hline & & & 3,78 & \\
\hline
\end{tabular}

Gambar 1.Garis Kontinum Motivasi Menjadi Host

Couchsurfing di Indonesia

Sumber : Olahan Peneliti, 2019

Faktor dengan nilai rata-rata terendah sebesar 2,81 yaitu faktor penghargaan. Pada faktor penghargaan mayoritas responden menyatakan ke sangat tidak setujuannya pada pernyataan "Saya menjadi host Couchsurfing agar mendapat hadiah dari tamu" dengan jumah $76 \%$, lalu diikuti dengan pernyataan "Saya menjadi host Couchsurfing agar dapat menabung" sebanyak 54\%. Dalam hal ini mayoritas host Couchsurfing sangat tidak setuju bahwa mereka menjadi host karena termotivasi oleh penghargaan yang berwujud dimana sesuai dengan konsep Couchsurfing yang disampaikan oleh Skog (2012) yaitu menawarkan akomodasi gratis, teman bicara, berbagi kegiatan, berbagi tips wisata serta mengenalkan budaya dan gaya hidup tertentu ditambah dengan pernyataan yang disampaikan oleh Sembiring (2017) bahwa Couchsurfing tidak membebankan biaya baik kepada host maupun surfer melainkan semua pelayanan diberikan secara sukarela.

Faktor dengan nilai rata-rata tertinggi sebesar 4,70 yaitu faktor kebudayaan, Pada faktor kebudayaan mayoritas responden menyatakan ke sangat setujuannya pada pernyataan "Saya menjadi host Couchsurfing agar dapat membagikan budaya saya sendiri" dengan jumlah $79 \%$, kemudian diikuti oleh pernyataan "Saya menjadi host Couchsurfing agar dapat mengenal tentang budaya tamu saya" sebanyak 74\%. Pietilä (2011) 
berpendapat bahwa faktor budaya itu penting karena kita hidup di dunia global dan menemukan budaya yang berbeda setiap hari.

\section{SIMPULAN DAN SARAN}

Simpulan

Dari hasil analisis tersebut menyatakan bahwa motivasi tertinggi menjadi host Couchsurfing bukan karena menginginkan hadiah nyata (uang atau barang) tetapi karena menginginkan adanya pertukaran budaya dengan wisatawan, baik mengetahui budaya yang dimiliki wisatawan maupun membagikan budaya sendiri. Selain itu, Couchsurfing merupakan bagian dari komunikasi pariwisata, dengan menjadi host, warga lokal bisa memanfaatkan pengetahuannya tentang budaya dan daerah setempat untuk menggaet kunjungan wisatawan secara langsung.

\section{Saran}

Dari faktor tertinggi motivasi menjadi host Couchsurfing menunjukkan bahwa untuk mendorong peningkatkan kegiatan pariwisata di Indonesia, pemerintah bisa melakukannya dengan meningkatkan aspek-aspek kebudayaan, melihat dari kebudayaan di Indonesia sangat beragam.Sedangkan untuk penelitian selanjutnya diharapkan dapat mencari informasi lebih dalam mengenai Couchsurfing, yaitu mengenai apakah ada pengaruhnya antara perkembangan suatu daerah potensi wisata di Indonesia dengan adanya Couchsurfing. 


\section{Kepustakaan}

Bungin, B. 2015. Komunikasi Pariwisata (Tourism Communication). Jakarta: Prenadamedia Group.

Chandra \& Darmajati. 2017. Tiga Tahun Jokowi-JK, Pariwisata Sumbang Devisa Terbesar Kedua. Detik Finance. https://finance.detik.com/beritaekonomi-bisnis/d-3687715/tiga-tahunjokowi-jk-pariwisata-sumbang-devisaterbesar-kedua diakses pada tanggal 17 September 2018.

Couchsurfing. Couchsurfing Hosts Indonesia. 2018.

https://www.couchsurfing.com/member s/hosts?utf $8=\% \mathrm{E} 2 \% 9 \mathrm{C} \% 93 \&$ search_typ $\mathrm{e}=$ host\&placeid $=$ ChIJtwRkSdcHTCwR hfStG-dNe-M\&search_query=Indonesia diakses pada 9 November 2018.

Kettunen, M. 2017. Re-think Agency in Alternative Tourism - Host's Motivations to Participate in Collaborative Economy. Tesis. Oulu: University of Oulu.

Nurmi, J.E. 1991. How Do Adolescents See Their Future? A review of The Development of Future Orientation and Planning. Developmental Review, 11.

Pietilä, Outi. 2011. CouchSurfers' Motivations to Host Travelers in Spain. Skripsi. Kerava: Laurea University.

Prastowo, A.A \& Budiana, H.R. 2016. Pengembangan Pola Komunikasi Pariwiwsata Berbasis Kearifan Lokal. Jurnal Ilmu Komunikasi, Vol.7, nomor 1. Bandung: Universitas Padjadjaran.

Priyandono. 2016. Komunikasi Persuasif. Jurnal. Surakarta: Universitas Selamet Riyadi.

Rizqia, T.D. 2011. Orientasi Masa Depan pada Remaja yang Mengalami Percaeraian Orang Tua. Skripsi. Surakarta: Universitas Muhammadiyah Surakarta.

Sembiring, F.BR. 2017. Eksistensi dan Motivasi Menjadi Host Couchsurfing di
Kota Denpasar. Skripsi. Bali: Universitas Udayana.

Skog, C. 2012. Couchsurfing- a choice for travelers. Skripsi. Helsinki: Haaga-Helia ammattikorkeakoulu.

Sobur, A. 2016. Psikologi Umum (6). Bandung: Pustaka Setia.

Sudjana, N. \& Ibrahim. 1989. Penelitian dan Penilaian Pendidikan. Bandung: Sinar Baru.

Sugiyono. 2018. Metode Penelitian Kuantitatif (1). Bandung: Alfabeta.

The Statistics Portal. 2018. Number of Social Networks Users Worldwide from 2010 to 2021 (in billions). The Statistics Portal.

https://www.statista.com/statistics/2784 14/number-of-worldwide-socialnetwork-users/ diakses pada tanggal 22 September 2018.

Walgito, Bimo. 2004. Pengantar Psikologi Umum. Yogyakarta. Andi Offset.

Wang, Y. \& Fesenmaier, D. R. 2003. Assessing Motivation of Contribution in Online Communities: An Empirical Investigation of an Online Travel Community. Journal of Electronic Markets, Vol 13. Diambil pada 12 Desember, 2018, dari https://pdfs.semanticscholar.org/b4d2/eb d4a2de90005283ec0908c9eed704670bd f.pdf. 